
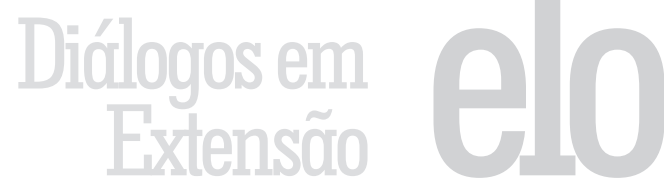

\title{
Produção de mudas nativas para a recuperação de áreas degradadas às margens do rio Paraguai
}

\author{
Lobato Pozo Barbosa ${ }^{1}$, Wagner da Cunha Siqueira², \\ Carlos Alberto da Cunha Oliveira ${ }^{3}$, Valteir Siani Ferreira ${ }^{4}$, \\ Selma Alves Abrahão ${ }^{5}$, Luciano Recart Romano ${ }^{6}$
}

\begin{abstract}
Resumo: Este trabalho teve como objetivo a produção de mudas para fins de recuperação de áreas degradadas às margens do rio Paraguai e seus afluentes no município de Cáceres, MT, visando, além da recomposição das matas ciliares, o bem estar da comunidade dos idosos que poderão frequentar este local. O processo de produção de mudas teve início no Instituto Federal de Educação, Ciências e Tecnologia de Mato Grosso (IFMT) - Campus Cáceres, no setor de Engenharia Florestal, com a construção do viveiro de mudas nativas. Entre as atividades desenvolvidas, primeiramente foi realizado um levantamento da demanda populacional de espécies nativas de área degradada às margens do rio Paraguai, posteriormente foi realizada a produção de mudas e o manejo das espécies produzidas. A produção das mudas contou com a participação dos acadêmicos do Curso de Engenharia Florestal, proporcionando conhecimento na identificação de espécies nativas e na produção de mudas. Após esta etapa, foi realizado o plantio das espécies nativas às margens do córrego "Maria Cabeluda", afluente do Rio Paraguai, que passa dentro do terreno da Associação Remanso Fraterno João Gabriel. O ato do plantio envolveu professores, alunos, voluntários e os idosos da associação, o que possibilitou a troca de conhecimento sobre educação ambiental, demonstrando a importância da preservação dos recursos naturais, assim como divulgou à comunidade a participação do Instituto Federal de Educação, Ciências e Tecnologia de Mato Grosso, Campus Cáceres, no apoio à preservação do meio ambiente e a socialização e troca de conhecimento entre a comunidade e os estudantes.
\end{abstract}

Palavras chave: Interação da comunidade, produção de mudas, recuperação de áreas degradadas

Áreas temáticas: Meio Ambiente, metodologias em extensão e teorias

\section{Production of native seedlings for the recovery of degraded areas at margins of the Paraguairiver}

Abstract: This work had as objective the production of seedlings for recovery of degraded areas at margins of the Paraguay river and its tributaries in Cáceres - MT, aiming recomposition of riparian vegetation besides the well-being of the community of elderly people who may attend this site. The process for the production of seedlings started at Instituto Federal de Educação, Ciência e

\footnotetext{
${ }^{1}$ Instituto Federal de Mato Grosso

2 Instituto Federal de Mato Grosso

${ }^{3}$ Instituto Federal de Mato Grosso

${ }^{4}$ Instituto Federal de Mato Grosso

${ }^{5}$ Instituto Federal de Mato Grosso

${ }^{6}$ Instituto Federal de Mato Grosso
} 
Tecnologia de MatoGrosso (IFMT) - Campus Cáceres in Forest Engineering with the construction of the nursery of native seedlings. Among the many activities, we first carried out a survey of the demand population of native species of degradedarea the margins of the Paraguayriver, subsequently, was conducted for seedling production and the management of species produced. The production of seedlings counted with the participation of the academic Course of Forest Engineering providing knowledge in the identification of native species and the production of seedlings. After this step, was performed the planting of native species the margins of "Maria cabeluda" creek tributary of the Paraguay river which passes within the terrain of the AssociaçãoRemansoFraternoJoano Gabriel. The act of planting involving teachers, students, volunteers and the elderly of the association which enabled the exchange of knowledge about environmental education, demonstrating the importance of preservation of natural resources, as well as issued to community the participation of Instituto Federal de Educação, Ciência e Tecnologia de MatoGrosso - Campus Cáceres in supporting the preservation of environment and socialization and exchange of knowledge between community and students.

Keywords: interaction with community, production of seedlings, recovery of degraded areas

\section{La producción de plantas nativas para la recuperación de la ribera del río Paraguay}

Resumen: Este estudio tuvo como objetivo producir plántulas para la recuperación de áreas degradadas en las orillas del río Paraguay y sus afluentes en la ciudad de Cáceres - MT, apuntando más allá de la restauración de los bosques de ribera, el bienestar de la comunidad de estudiantes que asistirán a esta ubicación. El proceso de producción de plántulas se inició en el Instituto Federal de Educação, Ciência e Tecnologia de Mato Grosso (IFMT)-Campus Cáceres en el sector forestal, con la construcción del vivero de plantas nativas. Entre las actividades, fue primero un estudio de la demanda de la población del área nativa degrada a orillas del río Paraguay, fue la producción de plántulas más tarde se celebró y la gestión de las especies producidas.La producción de plántulas, con la participación de académicos de los estudiantes Forestal proporcionando experiencia en la identificación de las especies nativas y la producción de plántulas. Después de este paso, se llevó a cabo la plantación de especies nativas corriente márgenes "Maria Cabeluda" afluente del Río Paraguay, que corre a través de la tierra de Associação Remanso Fraterno João Gabriel. El acto de plantación de profesores implicados, estudiantes, voluntarios y asociaciones mayores que permitió el intercambio de conocimientos sobre educación ambiental, lo que demuestra la importancia de la conservación de los recursos naturales, así como la comunidad anunció la participación del Instituto Federal de Educação, Ciência e Tecnologia de Mato Grosso- Campus Cáceres apoyan la preservación del medio ambiente y la socialización y el intercambio de conocimientos entre la comunidad y los estudiantes.

Palabras claves: producción de plántulas, la recuperación áreas degradadas, la interacción de la comunidad

\section{Introdução}

A medida provisória publicada na edição do dia 28 de maio de 2012 no Diário Oficial da União introduziu mais de trinta mudanças no novo Código Florestal - Lei 12.651/2012 (BRASIL, 2012), sancionado com vetos 
e igualmente publicado. Entre as alterações está a redução da exigência de recomposição de mata ciliar para pequenos produtores que plantaram em Área de Preservação Permanente (APP).

Em decorrência da legislação vigente que incorporou as mudanças expressas acima, em imóveis com área de um a dois módulos fiscais, será obrigatória a recomposição de faixa de mata de oito metros de largura, e em imóveis de dois a quatro módulos, serão quinze metros de mata, para rios de qualquer tamanho, sendo que cada módulo fiscal na região onde foi implantado o projeto equivale a oitenta hectares. A retirada da cobertura vegetal de áreas marginais para fins de criação de núcleos urbanos (cidades, bairros e vilas) está inserida no processo de ocupação territorial. Essa ocupação, por sua vez, geralmente acontece desordenadamente, sem a preocupação de um planejamento da área a ser ocupada, dificultando a gestão da área e causando problemas ao meio ambiente.

De acordo com o Código Florestal Brasileiro, as áreas marginais de cursos d'água são APP's - áreas que não podem ser utilizadas, exceto somente se for de interesse público. No Brasil, a legislação ambiental é bem restritiva com relação às APP's, mas apesar da legislação, a falta de planejamento urbano, de fiscalização de órgãos responsáveis e as pressões de atividades antrópicas vêm reduzindo cada vez mais essas áreas.

Devido a esses problemas, o trabalho teve como objetivo a produção de mudas para fins de recuperação de áreas degradadas às margens do rio Paraguai e seus afluentes no município de Cáceres - MT, visando além da recomposição das matas ciliares, o bem estar da comunidade dos idosos que poderão frequentar este local.

\section{Metodologia}

O trabalho foi desenvolvido com o apoio do Instituto Federal de Educação, Ciência e Tecnologia de Mato Grosso, sendo aprovado no edital N¹13/2012, publicado pela Pró-reitoria de Extensão do IFMT.

O levantamento das espécies nativas se deu pela coleta de sementes realizada às margens do rio Paraguai e de seus afluentes, localizados no município de Cáceres. A produção de mudas foi realizada no setor de Engenharia Florestal do Instituto Federal de Mato Grosso IFMT - Campus Cáceres.

O projeto foi implantado na Associação Remanso Fraterno João Gabriel (ARFJG), fundada em 05 de março de 2004, na cidade de Cáceres, Mato Grosso. A associação está localizada na região norte da cidade, no bairro Olhos D'água. Possui uma área de 4,5 hectares, na qual se encontra uma APP de aproximadamente 1 ha, porém degradada, que margeia o córrego "Maria Cabeluda"(antigo canal de irrigação e drenagem de lavoura de arroz). A ARFJG é uma entidade filantrópica que procura promover aos idosos, em todos os aspectos, bem estar social, cultural, econômico e espiritual, e atualmente consta em seu cadastro 150 (cento e cinquenta) idosos de oito bairros adjacentes ao bairro Cohab Nova. A ARFJG tem o apoio da Escola Estadual de $1^{\circ}$ e $2^{\circ}$ graus Ana Maria das Graças Noronha e desenvolve trabalhos com ajuda de voluntários da UNEMAT (Universidade Estadual de Mato GrossoCampus Cáceres), das áreas de educação física, enfermagem e educação. 
Para que os idosos pudessem usufruir dessa área com o intuito de formar uma trilha ecológica sem danificar o meio ambiente, a Secretaria Estadual do Meio Ambiente (SEMA) disponibilizou orientações a respeito da utilização dessa área pela associação. No entanto, seria necessária a recuperação da mata ciliar com o mínimo 50m das margens do córrego, área maior que a prevista na lei 12.651/12, relacionada com a largura do córrego que tem aproximadamente $2 \mathrm{~m}$, e em relação aos módulos fiscais. Foi a partir dessa decisão que a ARFJG, junto com jovens do grupo Demolay ligados à loja maçônica, iniciaram a recuperação da área com um plantio de aproximadamente 500 mudas nativas. Porém, essas mudas não foram suficientes para a recuperação de toda a área. Dessa forma, a ARFJG entrou em contato com o IFMT-Campus Cáceres e criou uma parceria com o objetivo de a Instituição desenvolver um trabalho ambiental e produzir as mudas a serem plantadas na área.

O processo de recuperação da área ocorreu em algumas etapas: construção do viveiro, identificação das árvores, coletas de sementes, produção e manejo das mudas nativas e plantio.

A construção do viveiro de mudas nativas foi realizada pelos acadêmicos do curso de Engenharia Florestal e voluntários (Figura 1). Para atender a demanda de mudas, o viveiro foi construído com um tamanho de $10 \mathrm{~m}$ de largura e 20m de comprimento, contendo as três fases de aclimatação: $80 \%$ de sombreamento, $50 \%$ de sombreamento e a céu aberto.

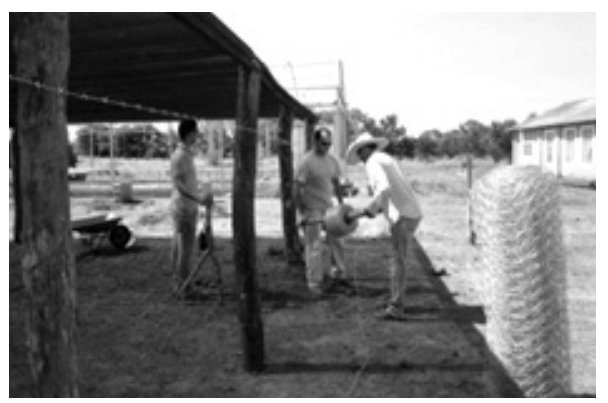

Figura 1 - Construção do viveiro

Após a conclusão da obra do viveiro, foi realizado um levantamento da demanda populacional de espécies nativas de área degradada às margens do rio Paraguai e seus afluentes. O objetivo deste levantamento foi identificar as espécies que se encontravam naquela região para realizar as coletas de sementes. A identificação das espécies e a coleta de sementes foram realizadas com a colaboração de moradores da região que tinham maior acesso à área e conheciam as espécies que ali se encontravam. Essa interação dos colaboradores com os estudantes proporcionou a troca de conhecimentos práticos e teóricos entre eles.

A produção de mudas e o seu manejo (Figura 2) também foram realizados pelos estudantes, porém, com auxílio dos professores de Engenharia Florestal do IFMT- Campus Cáceres. Nessa etapa, foram realizadas atividades como: preparo de sementeiras, enchimento de sacos plásticos, transplante das mudas, irrigação. Isso permitiu que os estudantes colocassem seus conhecimentos em prática, preparando-os para o mercado de trabalho. 
O plantio (Figura 3) teve a colaboração da comunidade dos idosos, que por sua vez, foram e serão beneficiados futuramente com as trilhas ecológicas. Os serviços, como preparo da área para o plantio e coveamento, foram realizados pelos estudantes e colaboradores, já o plantio e as regas das mudastiveram a participação da comunidade de idosos. Essas atividades envolveram os idosos e voluntários trazendo-lhes benefícios físicos, mentais e de socialização.

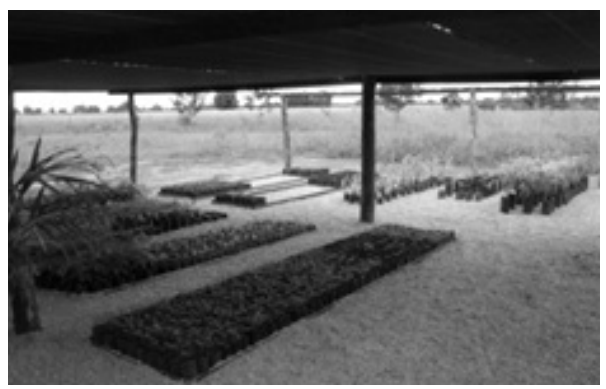

Figura 2 - Produção de mudas nativas

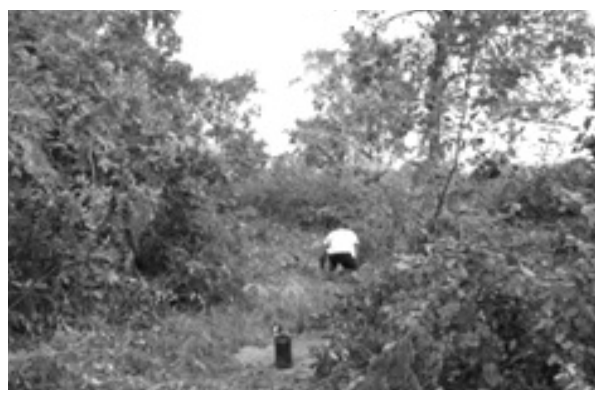

Figura 3 - Plantio das mudas

\section{Resultados}

Foram produzidas aproximadamente mil mudas, sendo estas pertencentes às seguintes espécies: Jacarandá (Jacaranda brasilianaLam.); Lixeira (Curatella americanaL.); Aroeira (Myracrodruon urundeuva Fr. Allen); Novateiro (Triplaris americana L.);Ipê-preto (Handroanthus arianeae A.H. Gentry); Cambará (Vochysia divergensPohl.). Essas espécies não apresentaram dormência nas sementes, resultando num bom percentual de germinação.

As mudas foram plantadas em um período de escassez de chuva, por esse motivo, somente quatrocentas mudas foram encaminhadas para o local, sendo necessário fazer a irrigação após o plantio.

A educação ambiental é um dos principais passos para que se possa valorizar os recursos naturais visando preparar o ser humano para uma vida de qualidade. A educação ambiental disponibiliza conhecimentos que favorecem o gerenciamento das relações entre a nossa sociedade e o meio ambiente, de uma forma sustentável. Um dos principais resultados desse projeto, além da produção e plantio das mudas, foi a conscientização da Associação, voluntários e estudantes com relação à vegetação das matas ciliares e à recuperação das áreas degradadas às margens de afluentes do rio Paraguai. 
A interação dos professores com os estudantes e com a comunidade dos idosos e voluntários possibilitou incorporar o conceito de Educação Ambiental e a importância da preservação dos recursos naturais, além de divulgar a participação do IFMT- Campus Cáceres no apoio à preservação ao meio ambienteà comunidade.

Segundo o comentário do Presidente da ARFJG, Professor Gilmar Batista Marostega, são muitos os benefícios decorrentes das atividades de extensão acadêmica, como se pode atestar em seu relato a seguir:

O trabalho de extensão dos alunos do curso de Engenharia Florestal na APP da ARFJG é importante por vários motivos: primeiro, poderíamos citar a questão ambiental- recomposição da flora do Cerrado numa área de preservação permanente, aumentando o número de árvores e espécies da mata ciliar; segundo, a integração/interação com os idosos participantes do projeto, cuja finalidade é a formação de trilha ecológica para caminhada dos mesmos e, terceiro, e não menos importante, o exercício de uma atividade de extensão e de voluntários, com excelentes resultados para a formação acadêmica e de cidadania dos respectivos estudantes. (comentário do Presidente da ARFJG, Professor Gilmar Batista Marostega)

\section{Conclusão}

Essa experiência foi produtiva, pois os envolvidos neste projeto puderam trocar conhecimentos, além de os idosos e voluntários terem tido a oportunidade de conhecer um pouco a mais da importância das matas ciliares e os benefícios que elas possam trazer ao meio ambiente, por exemplo, na preservação dos recursos hídricos e, por conseguinte, ao ser humano.

\section{Agradecimento}

Ao Instituto Federal de Educação, Ciência e Tecnologia de Mato Grosso Campus Cáceres, por financiar e apoiar a realização do trabalho.

\section{Referência Bibliográfica}

BRASIL. Medida provisória $n^{\circ}$ 571/2012. Altera a Lei $\mathrm{n}^{\circ} 12.651$, de 25 de maio de 2012, que dispõe sobre a proteção da vegetação nativa. Diário Oficial [da] República Federativa do Brasil, Brasília, DF, 28 de maio 2012. 